\title{
Street dust geochemistry in northern and eastern urban areas of São Paulo city, Brazil.
}

\author{
BOUROTTE C. ${ }^{1 *}$, IRES P.R. ${ }^{1}$
}

${ }^{1}$ IGc-USP, rua do lago 562, CEP 05508-080 São Paulo-SP, Brazil, (*correspondence: chrisbourotte@usp.br; raquel.ires@usp.br)

Urban geochemistry is on concern around the world. Since the occurrence and distribution of metals in Brazilian street dust is little known, the aim of this study is to discuss the trace metals concentration distribution and sources in street dust sampled at the northern (ZN) and eastern (ZL) areas of the São Paulo city, the largest metropolis of South America.

Street dust samples were collected using brush and plastic pan, in $3 \mathrm{~m}^{2}$ area that included gutter area and part of asphaltic pavement of the road. In $\mathrm{ZN}$, samples were collected in residential $(50 \%)$, commercial $(21 \%)$ and close to intense traffic roads $(29 \%)$. In $\mathrm{ZL}$, street dust was sampled in commercial (33\%), residential (50\%) and mixed areas $(17 \%)$. Samples were air-dried at room temperature and passed through a $2 \mathrm{~mm}$ mesh nylon sieve to remove stones, grass, leaves or any other greater materials (cigarette butt, plastic, etc.). All samples were homogenized and quartered. Samples were submitted to particle size analyses, X-Ray Diffraction analyses and SEM-EDS characterization. Major elements and trace metals were quantified by ICP-MS after microwave acid digestion. For both areas, fine sand fraction was predominant $(\sim 30 \%)$. Silt fraction and clay fraction were greater in northern and eastern area of the city, respectively. Primary minerals such as quartz, feldspar, clay minerals and carbonate were identified. SEM analyses showed different kind of particles from natural or anthropogenic sources such as primary minerals, zircon, barite, monazite, biogenic particles, metallic spheres, agglomerates, tire debris and metallic fragments. For major elements, highest concentration in $\mathrm{ZN}$ and $\mathrm{ZL}$ are Fe and $\mathrm{Al}$, respectively. For trace metals, $\mathrm{Zn}$ showed the highest average concentration $(263 \pm 106$ mg. $\mathrm{kg}^{-1}$ in $\mathrm{ZL}$ and $190 \pm 88 \mathrm{mg} \cdot \mathrm{kg}^{-1}$ in $\mathrm{ZN}$ ) and then $\mathrm{Ba}>\mathrm{Cu}>\mathrm{Pb}>\mathrm{Cr}>\mathrm{V}>\mathrm{Cd}>\mathrm{Ni}$ in both area but concentration are $28 \%$ to $55 \%$ higher in ZL. Other trace metals (Co, Sn, Mo, $\mathrm{As}, \mathrm{Sb}$ ) and metals are also higher in $\mathrm{ZL}$ area, except for $\mathrm{Ti}$ and $\mathrm{Mn}$. Some trace metals may be associated with tire wears (Al, $\mathrm{Si}, \mathrm{Ca}, \mathrm{Zn})$ and brake abrasion dusts $(\mathrm{Fe}, \mathrm{Cu}, \mathrm{Sb}, \mathrm{Ti}, \mathrm{Ba}$, $\mathrm{Cr}, \mathrm{Ni})$, street painting $(\mathrm{Cr}, \mathrm{Pb})$. Higher concentrations in $\mathrm{ZL}$ can be explained by passive industrial history of this region. Trace metals can also be transferred to atmosphere and hydrosphere and affect human health in urban environment if fine fraction will be resuspended. Metal isotopes will better track sources and transfer processes.

Acknowledgement: FAPESP (2010/20835-1). 